\title{
Internal friction of R-phase and B19' martensite in equiatomic TiNi shape memory alloy under isothermal conditions
}

\author{
S.H. Chang, S.K. Wu* \\ Department of Materials Science and Engineering, National Taiwan University, Taipei 106, Taiwan \\ Received 6 May 2006; received in revised form 19 July 2006; accepted 19 July 2006 \\ Available online 6 September 2006
}

\begin{abstract}
The intrinsic internal friction $\mathrm{IF}_{\mathrm{I}}$ of R-phase and $\mathrm{B} 19^{\prime}$ martensite are composed of static internal friction $\mathrm{IF}_{\mathrm{S}}$ and dynamic internal friction $\mathrm{IF}_{\mathrm{D}}$. The $\tan \delta$ values of $\mathrm{IF}_{\mathrm{S}}^{\mathrm{R}}$ and $\mathrm{IF}_{\mathrm{S}}^{\mathrm{B} 19^{\prime}}$ are both proportional to $\sigma_{0} / v^{1 / 2}$ and are related to the stress-assisted motions of twin boundaries. The tan $\delta$ values of $\mathrm{IF}_{\mathrm{S}}^{\mathrm{R}}$ are higher than those of $\mathrm{IF}_{\mathrm{S}}^{\mathrm{B} 19^{\prime}}$ is owing to the softer storage modulus $E_{0}$ in R-phase. The $\tan \delta$ values of $\mathrm{IF}_{\mathrm{D}}^{\mathrm{B} 19^{\prime}}$ are linearly proportional to $\dot{T} / v^{1 / 2}$. The occurrence of relaxation peak at $\approx-60^{\circ} \mathrm{C}$ is found to come from the $\mathrm{IF}_{\mathrm{S}}^{\mathrm{B} 19^{\prime}}$, instead of the $\mathrm{IF}_{\mathrm{D}}^{\mathrm{B} 19^{\prime}}$.

(C) 2006 Elsevier B.V. All rights reserved.

Keywords: Shape memory alloy; Thermal (dynamic mechanical) analysis; Internal friction; Martensite
\end{abstract}

\section{Introduction}

TiNi alloys are known as important shape memory alloys (SMAs) because of their functional properties such as shape memory effect and superelasticity [1]. Many reported studies revealed that TiNi SMAs exhibit a high internal friction peak associated with a shear modulus minimum during martensitic transformation and thus are suitable for the energy dissipation applications [2-9]. The damping characteristics of internal friction peak during martensitic transformation are associated with experimental parameters such as temperature rate $\dot{T}$, frequency $v$ and amplitude $\sigma_{0}$. It is also reported that both R-phase premartensite and B19' martensite in TiNi SMAs perform a high damping property due to the easy movement of their twin boundaries in between the variants [5]. Besides, the occurrence of R-phase can strongly soften the storage modulus $E_{0}$ and thus promotes the TiNi SMAs' damping capacity [10]. In addition to the internal friction peaks in TiNi SMAs, there is also a relaxation peak appearing at temperature around $200 \mathrm{~K}$. Iwasaki and Hasiguti [2] proposed that this relaxation peak is thermally activated and originates from dislocations.

It has been proposed that the internal friction of a first-order phase transformation can be decomposed into three terms: $\mathrm{IF}_{\mathrm{Tr}}$,

\footnotetext{
* Corresponding author. Tel.: +88622363 7846; fax: +886223634562.

E-mail address: skw@ntu.edu.tw (S.K.Wu).
}

$\mathrm{IF}_{\mathrm{PT}}$ and $\mathrm{IF}_{\mathrm{I}}[11-17]$. The first term $\mathrm{IF}_{\mathrm{Tr}}$ is the transitory internal friction which appears only at low $v$ and non-zero $\dot{T}$. It depends on external parameters such as $\dot{T}, v, \sigma_{0}$ and volume fraction transformed per unit time. The second term $\mathrm{IF}_{\mathrm{PT}}$ is the internal friction due to the phase transformation, but it does not depend on $\dot{T}$. The third term $\mathrm{IF}_{\mathrm{I}}$ is the intrinsic internal friction of austenitic or martensitic phase measured at constant $\dot{T}$ and strongly dependent on microstructure properties such as dislocations, vacancies and twin boundaries. In the low frequency range, the internal friction peak observed during transformation is mainly ascribed to the first term $\mathrm{IF}_{\mathrm{Tr}}$. In equiatomic TiNi SMA, Chang and Wu [18] reported that the inherent internal friction $\left(\mathrm{IF}_{\mathrm{PT}}+\mathrm{IF}_{\mathrm{I}}\right)$ measured under isothermal conditions during $\mathrm{B} 2 \rightarrow \mathrm{R}$ and $\mathrm{R} \rightarrow \mathrm{B} 19^{\prime}$ martensitic transformation are linearly proportional to $\sigma_{0} / v^{1 / 2}$ but independent of $\dot{T}$. The damping mechanism of the inherent internal friction $\left(\mathrm{IF}_{\mathrm{PT}}+\mathrm{IF}_{\mathrm{I}}\right)$ is mainly generated from the stress-assisted martensitic transformation and stress-assisted motions of twin boundaries. However, all the reported studies focus on the damping characteristics of transitory and inherent internal friction $\left(\mathrm{IF}_{\mathrm{Tr}}, \mathrm{IF}_{\mathrm{I}}\right.$ or $\left.\mathrm{IF}_{\mathrm{PT}}+\mathrm{IF}_{\mathrm{I}}\right)$ during martensitic transformation. The damping characteristics of the single phase in TiNi SMAs, such as B2 parent phase, R-phase premartensite and $\mathrm{B} 19^{\prime}$ martensite, under isothermal conditions have not been systematically studied before. In this study, the damping capacity $\tan \delta$ values of a $\mathrm{Ti}_{50} \mathrm{Ni}_{50}$ SMA which exhibits a two-stage $\mathrm{B} 2 \rightarrow \mathrm{R} \rightarrow \mathrm{B} 19^{\prime}$ martensitic transformation during cooling are measured by dynamic mechanical 
analyzer (DMA) under isothermal conditions at different temperatures. Thereafter, the isothermal damping characteristics of each single phase: B2, R-phase and B19' martensite are discussed.

\section{Experimental procedures}

Equiatomic $\mathrm{Ti}_{50} \mathrm{Ni}_{50}$ alloy was prepared by conventional vacuum arc remelting. The as-melted ingot was hot-rolled at $850^{\circ} \mathrm{C}$ into a $2 \mathrm{~mm}$ thick plate and then the plate was solution-treated at $850^{\circ} \mathrm{C}$ for $2 \mathrm{~h}$ followed by quenching in water. Then, the plate was cold-rolled at room temperature along the hot-rolling direction and reached a final 30\% thickness reduction. Subsequently, the cold-rolled plate was cut into test specimens with the dimension of $40 \mathrm{~mm} \times 5 \mathrm{~mm} \times 1.26 \mathrm{~mm}$, sealed in an evacuated quartz tube and annealed at $650{ }^{\circ} \mathrm{C}$ for $2 \mathrm{~min}$. The detailed procedure for preparing specimen is demonstrated in another paper [18].

Transformation temperatures of cold-rolled and annealed specimen were determined by differential scanning calorimetry (DSC) test using a TA Q10 DSC equipment with a constant cooling rate of $10^{\circ} \mathrm{C} / \mathrm{min}$. Specimen for DMA experiment was cut along the rolling direction to eliminate the influence of rolling texture [19]. The $\tan \delta$ and storage modulus $E_{0}$ were measured by a TA 2980 DMA equipment using a constant cooling rate of $3{ }^{\circ} \mathrm{C} / \mathrm{min}$. The isothermal damping characteristics of $\mathrm{B} 2, \mathrm{R}$-phase and $\mathrm{B} 19^{\prime}$ martensite were also investigated by DMA but tested under isothermal conditions using various amplitudes and frequencies. The detailed procedure for the isothermal DMA test was conducted as follows. The specimen was initially cooled starting from $150^{\circ} \mathrm{C}$ at a constant cooling rate $\left(1,3\right.$ or $\left.5^{\circ} \mathrm{C} / \mathrm{min}\right)$ and was kept isothermally for $30 \mathrm{~min}$ at the set temperature. After being isothermal for $30 \mathrm{~min}$, the specimen was heated up to $150^{\circ} \mathrm{C}$ to ensure it had returned to $\mathrm{B} 2$ parent phase. Then, the specimen was cooled to another set temperature and kept isothermally at that temperature for $30 \mathrm{~min}$. During the isothermal conditions, the set temperature was chosen in between $+80^{\circ} \mathrm{C}$ and $-80^{\circ} \mathrm{C}$ in which B2, R-phase and $\mathrm{B} 19^{\prime}$ martensite are all included.

\section{Experimental results}

\subsection{DSC and DMA measurements at constant $\dot{T}$}

Fig. 1 shows the DSC and DMA curves of $30 \%$ cold-rolled $\mathrm{Ti}_{50} \mathrm{Ni}_{50}$ alloy annealed at $650^{\circ} \mathrm{C}$ for $2 \mathrm{~min}$. As shown in Fig. 1, there are two transformation peaks, i.e. B2 $\rightarrow \mathrm{R}$ and $\mathrm{R} \rightarrow \mathrm{B} 19^{\prime}$ obtained in DSC cooling curve. There are also two transformation peaks appearing in the $\tan \delta$ curve which correspond to $\mathrm{B} 2 \rightarrow \mathrm{R}$ and $\mathrm{R} \rightarrow{\mathrm{B} 19^{\prime}}^{\prime}$ transformation peaks in DSC curve. Except the aforementioned $\tan \delta \operatorname{transformation~peaks,~an~extra~broad~peak~which~is~not~observed~}$ in DSC curve appears at about $-65^{\circ} \mathrm{C}$ in $\tan \delta$ curve. This extra broad peak is

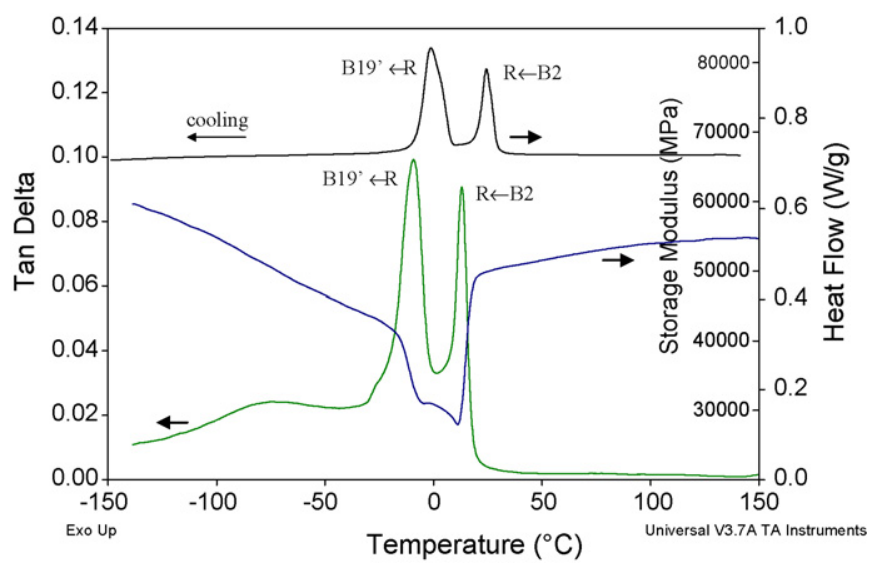

Fig. 1. DSC curve measured at $\dot{T}=10^{\circ} \mathrm{C} / \mathrm{min}$ and DMA curves measured at $\dot{T}=1{ }^{\circ} \mathrm{C} / \mathrm{min}, v=1 \mathrm{~Hz}$ and $\sigma_{0}=5 \mu \mathrm{m}$ for $30 \%$ cold-rolled $\mathrm{Ti}_{50} \mathrm{Ni}_{50}$ alloy annealed at $650{ }^{\circ} \mathrm{C}$ for $2 \mathrm{~min}$.

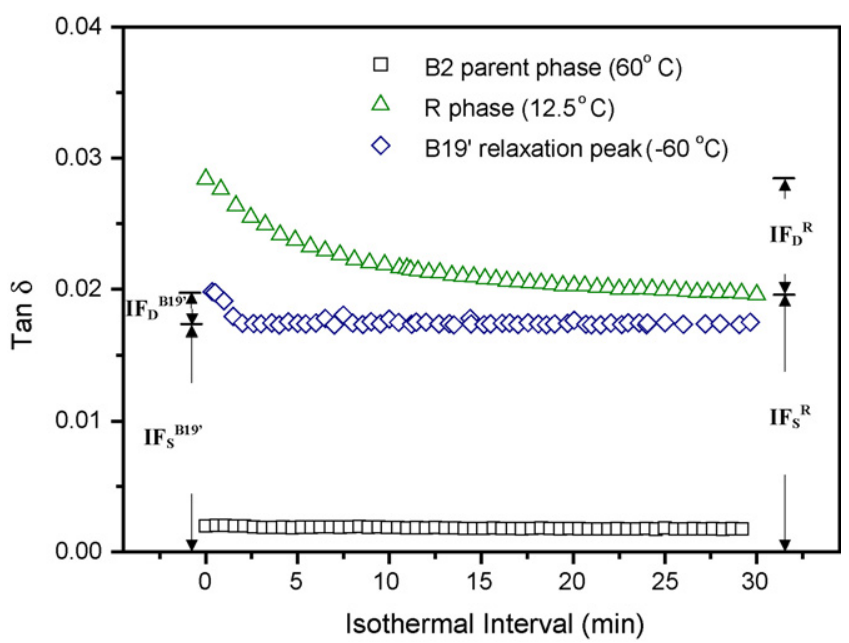

Fig. 2. The $\tan \delta$ values vs. isothermal interval for Fig. 1 specimen measured at $v=1 \mathrm{~Hz}, \sigma_{0}=5 \mu \mathrm{m}$. The selected isothermal temperatures are $60^{\circ} \mathrm{C}$ (B2 phase), $12.5^{\circ} \mathrm{C}$ (R-phase) and $-60^{\circ} \mathrm{C}\left(\mathrm{B} 19^{\prime}\right.$ martensite).

known as the relaxation peak [2,4]. Also from Fig. 1, the $E_{0}$ curve declines gently in B2 parent phase while cooling, then drops drastically and exhibits a deeper minimum during $\mathrm{B} 2 \rightarrow \mathrm{R}$ transformation and a shallower minimum during $\mathrm{R} \rightarrow \mathrm{B} 19^{\prime}$ transformation. After $\mathrm{R} \rightarrow \mathrm{B} 19^{\prime}$ transformation completes, the $E_{0}$ value of B19' martensite increases quickly with decreasing temperature.

\subsection{DMA measurement under isothermal conditions}

Fig. 2 plots the $\tan \delta$ values versus isothermal interval when the specimen of Fig. 1 is tested by DMA under isothermal treatment at $60^{\circ} \mathrm{C}$ (B2 parent phase), $12.5^{\circ} \mathrm{C}$ (R-phase) and $-60^{\circ} \mathrm{C}$ (B19' martensite) for 0-30 min. As shown in Fig. 2, the measured $\tan \delta$ values of B2 parent phase are almost the same in the whole isothermal conditions. However, both the measured $\tan \delta$ values of R-phase and B19' martensite decrease with increasing isothermal intervals and reach a steady value after $10-15 \mathrm{~min}$. As illustrated in Fig. 2, the $\tan \delta$ values of R-phase and B19' martensite are composed of a dynamic term $\mathrm{IF}_{\mathrm{D}}$ which diminishes during isothermal conditions and a static term $\mathrm{IF}_{\mathrm{S}}$ which is the steady value measured after $30 \mathrm{~min}$ of isothermal interval.

In order to investigate the damping characteristics of $\mathrm{IF}_{\mathrm{S}}$ and $\mathrm{IF}_{\mathrm{D}}$ for $\mathrm{B} 2, \mathrm{R}$ phase and B19' martensite under isothermal conditions, DMA $\tan \delta$ tests under $30 \mathrm{~min}$ isothermal interval at different temperatures were conducted with various $\dot{T}, v, \sigma_{0}$ and the results are exhibited in Figs. 3-5, respectively. Fig. 3(a)-(c) show the $\tan \delta$ curves (empty mark curves) measured after $30 \mathrm{~min}$ isothermal interval at different temperatures when the specimen is conducted at the cooling rate $\dot{T}$ of 1,3 and $5^{\circ} \mathrm{C} / \mathrm{min}$, respectively, before it reaches the set isothermal temperature. The solid lines in Fig. 3(a)-(c) represent the $\tan \delta$ curves measured at constant $\dot{T}$ of 1,3 and $5{ }^{\circ} \mathrm{C} / \mathrm{min}$, respectively. Fig. 4(a)-(c) show the $\tan \delta$ curves measured after $30 \mathrm{~min}$ isothermal condition (empty mark curves) at different $v$ of $0.1,1$ and $10 \mathrm{~Hz}$, respectively. Fig. 5(a)-(c) are the $\tan \delta$ curves measured after $30 \mathrm{~min}$ isothermal condition (empty mark curves) at different $\sigma_{0}$ of 5,10 and $15 \mu \mathrm{m}$, respectively. In Figs. 4 and 5, the $\tan \delta$ curves measured at constant $\dot{T}$ (solid line curves, $\dot{T}=1{ }^{\circ} \mathrm{C} / \mathrm{min}$ ) are also plotted for comparison. As shown in Figs. 3-5, all the $\tan \delta$ values of $\mathrm{B} 2$ parent phase measured after isothermal conditions, i.e. $\mathrm{IF}_{\mathrm{S}}^{\mathrm{B} 2}$, are quite low and approximately same as those measured at constant $\dot{T}$ $\left(\mathrm{IF}_{\mathrm{I}}^{\mathrm{B} 2}\right)$. The $\tan \delta$ values of $\mathrm{R}$-phase measured after isothermal conditions, i.e. $\mathrm{IF}_{\mathrm{S}}^{\mathrm{R}}$, are much higher than those of $\mathrm{IF}_{\mathrm{I}}^{\mathrm{B} 2}$. However, the $\tan \delta$ values of $\mathrm{B} 19^{\prime}$ martensite measured after isothermal conditions, i.e. $\mathrm{IF}_{\mathrm{S}}^{\mathrm{B} 19^{\prime}}$, decline quickly after $\mathrm{R} \rightarrow \mathrm{B} 19^{\prime}$ transformation completes. With further isothermal treatment at lower temperatures, the $\tan \delta$ values of $\mathrm{IF}_{\mathrm{S}}^{\mathrm{B} 19^{\prime}}$ also exhibit a relaxation peak at around $-60^{\circ}$ C. Fig. 6 enlarges the diagram of B $19^{\prime}$ martensite region in Fig. 3(a) so to describe the decayed and steady $\tan \delta$ values measured under isothermal conditions. As illustrated in Fig. 6, the intrinsic internal friction $\mathrm{IF}_{\mathrm{I}} \mathrm{B} 19^{\prime}$ of $\mathrm{B} 19^{\prime}$ martensite measured at constant $\dot{T}$ is composed of $\mathrm{IF}_{\mathrm{S}}^{\mathrm{B} 19^{\prime}}$ and $\mathrm{IF}_{\mathrm{D}}^{\mathrm{B} 19^{\prime}}$. 

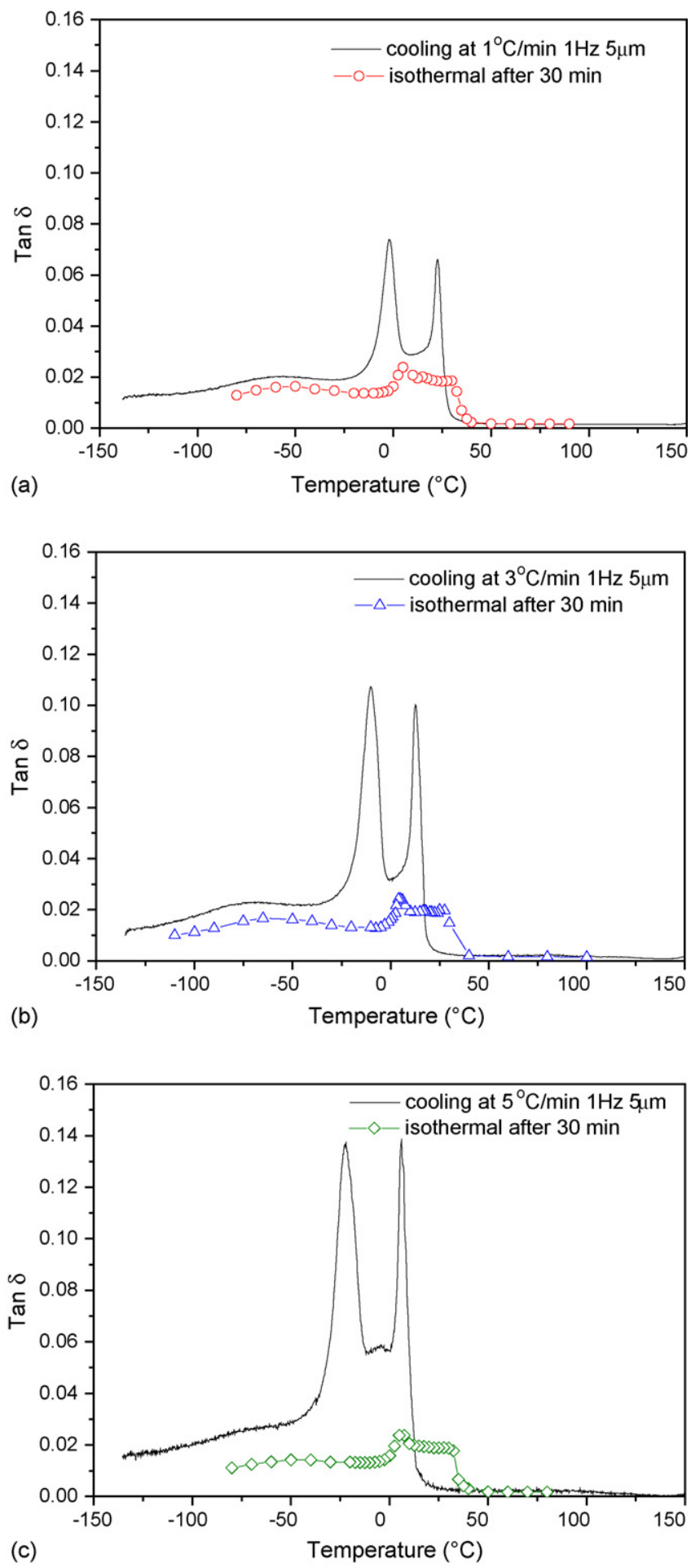

Fig. 3. The intrinsic $\tan \delta$ curves measured under isothermal conditions at $v=1 \mathrm{~Hz}$ and $\sigma_{0}=5 \mu \mathrm{m}$ with different cooling rates of (a) $\dot{T}=1{ }^{\circ} \mathrm{C} / \mathrm{min}$ (empty circle curve); (b) $\dot{T}=3{ }^{\circ} \mathrm{C} / \mathrm{min}$ (empty triangle curve); and (c) $\dot{T}=5^{\circ} \mathrm{C} / \mathrm{min}$ (empty diamond curve).

\section{Discussion}

\subsection{IF of $B 2$ parent phase, $R$-phase and $B 19^{\prime}$ martensite}

From the DMA results exhibited in Figs. 3-5, all the internal friction of $\mathrm{IF}_{\mathrm{S}}^{\mathrm{B} 2}$ are very low and their $\tan \delta$ values associated
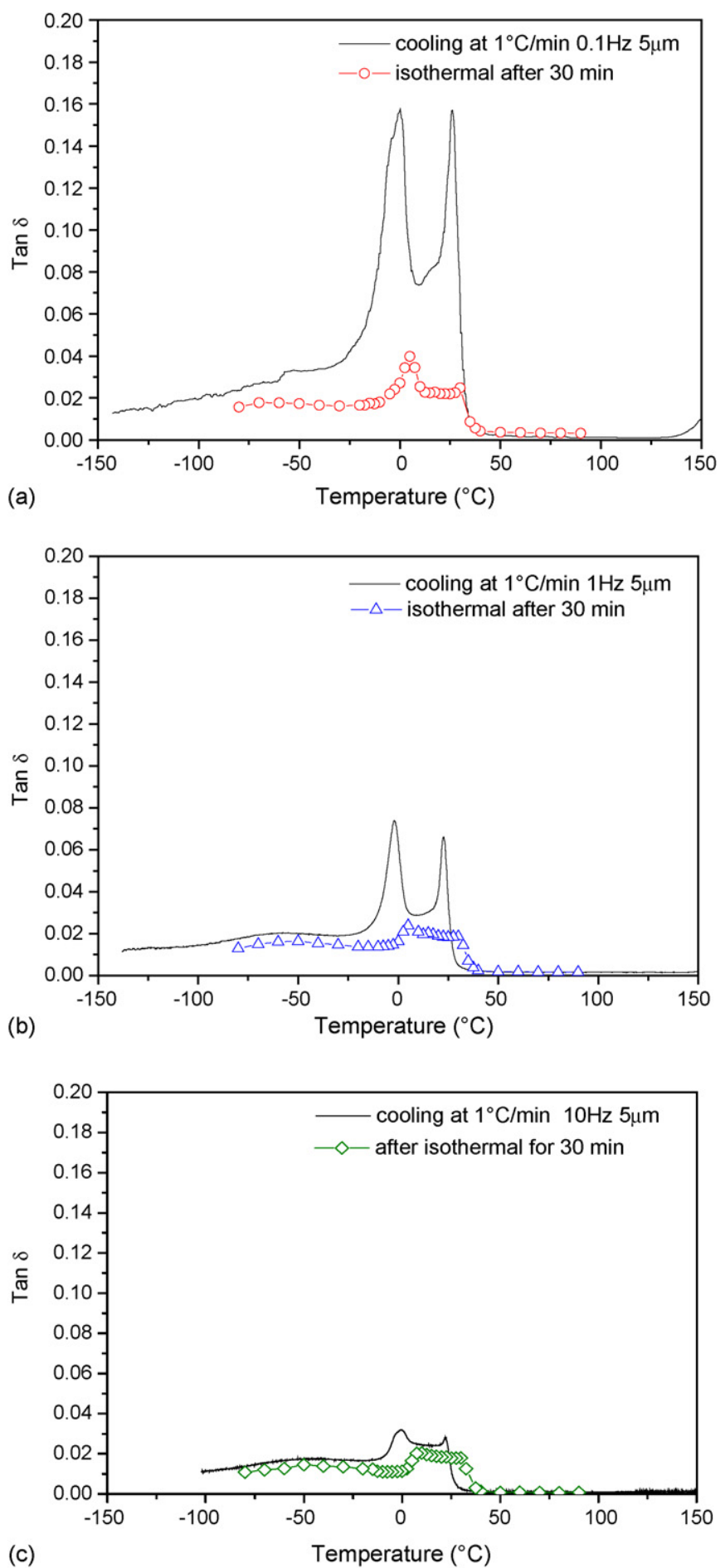

Fig. 4. The intrinsic $\tan \delta$ curves measured under isothermal conditions at $\dot{T}=$ $1{ }^{\circ} \mathrm{C} / \mathrm{min}$ and $\sigma_{0}=5 \mu \mathrm{m}$ with different frequencies of (a) $v=0.1 \mathrm{~Hz}$ (empty circle curve); (b) $v=1 \mathrm{~Hz}$ (empty triangle curve); and (c) $v=10 \mathrm{~Hz}$ (empty diamond curve).

with $\dot{T}, v$ and $\sigma_{0}$ are inconspicuous to investigate. Thus, only the effects of $\dot{T}, v$ and $\sigma_{0}$ on $\mathrm{IF}_{\mathrm{S}}^{\mathrm{R}}$ and $\mathrm{IF}_{\mathrm{S}}^{\mathrm{B} 19^{\prime}}$ are discussed in the following. Fig. 7(a) plots the $\tan \delta$ values of $\mathrm{IF}_{\mathrm{S}}^{\mathrm{R}}$ and $\mathrm{IF}_{\mathrm{S}}^{\mathrm{B} 19^{\prime}}$ as a function of $\dot{T}$ measured at $20^{\circ} \mathrm{C}$ and $-20^{\circ} \mathrm{C}$, respectively, in Fig. 3. From Fig. 7(a), both the $\tan \delta$ values of $\mathrm{IF}_{\mathrm{S}}^{\mathrm{R}}$ and $\mathrm{IF}_{\mathrm{S}}^{\mathrm{B} 19^{\prime}}$ almost keep constant when measured at different $\dot{T}$. This fea- 

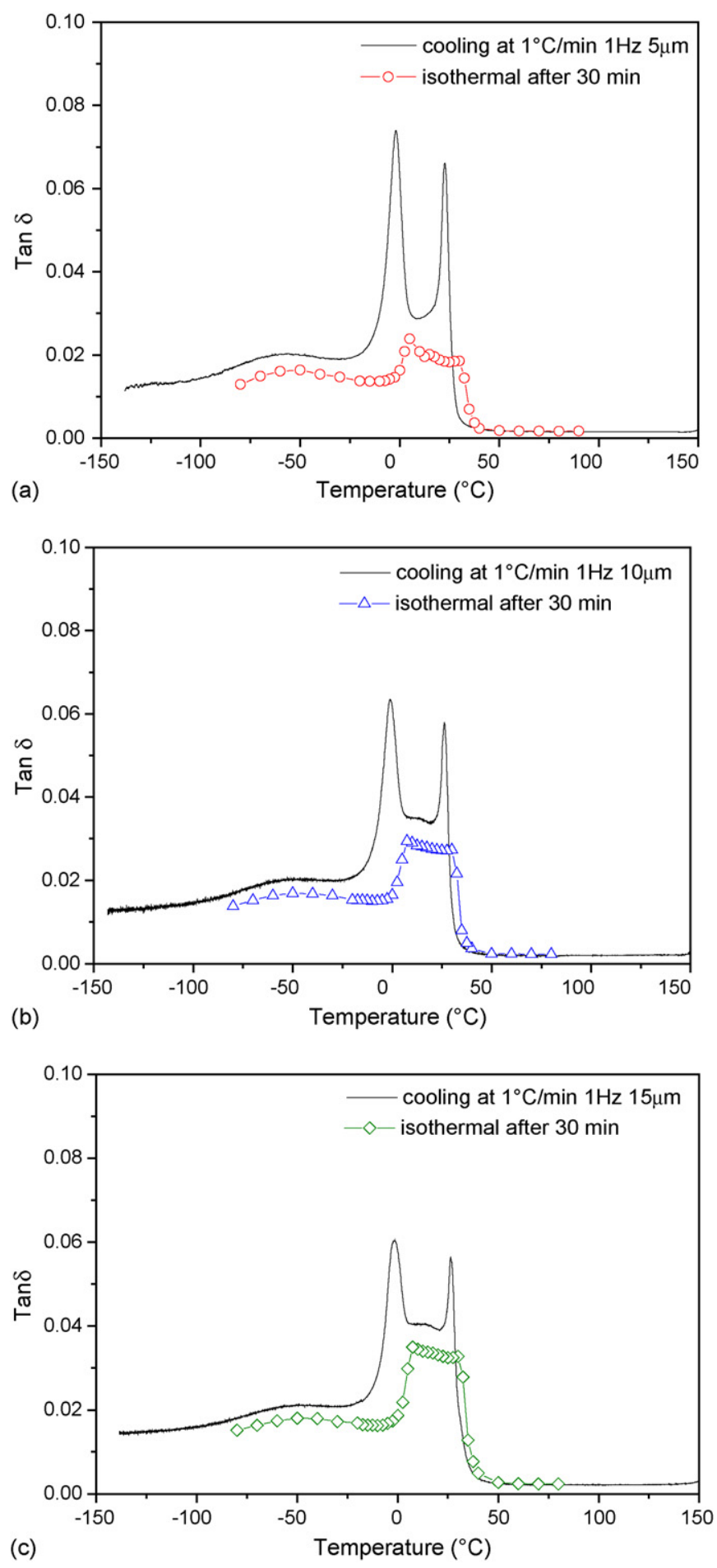

Fig. 5. The intrinsic $\tan \delta$ curves measured under isothermal conditions at $\dot{T}=1{ }^{\circ} \mathrm{C} /$ min and $v=1 \mathrm{~Hz}$ with different amplitudes of (a) $\sigma_{0}=5 \mu \mathrm{m}$ (empty circle curve); (b) $\sigma_{0}=10 \mu \mathrm{m}$ (empty triangle curve); and (c) $\sigma_{0}=15 \mu \mathrm{m}$ (empty diamond curve)

ture indicates that the $\tan \delta$ values of $\mathrm{IF}_{\mathrm{S}}^{\mathrm{R}}$ and $\mathrm{IF}_{\mathrm{S}}^{\mathrm{B} 19^{\prime}}$ are both independent of $\dot{T}$. Fig. 7(b) and (c) plot the $\tan \delta$ values of $\mathrm{IF}_{\mathrm{S}}^{\mathrm{R}}$ and $\mathrm{IF}_{\mathrm{S}}^{\mathrm{B} 19^{\prime}}$ as a function of $1 / v^{1 / 2}$ and $\sigma_{0}$ measured at $20^{\circ} \mathrm{C}$ and $-20^{\circ} \mathrm{C}$, respectively, in Figs. 4 and 5. As seen in Fig. 7, both $\mathrm{IF}_{\mathrm{S}}^{\mathrm{R}}$ and $\mathrm{IF}_{\mathrm{S}}^{\mathrm{B} 19^{\prime}}$ are linearly proportional to $\sigma_{0} / v^{1 / 2}$ but independent of $\dot{T}$ when the applied $v$ and $\sigma_{0}$ are in between

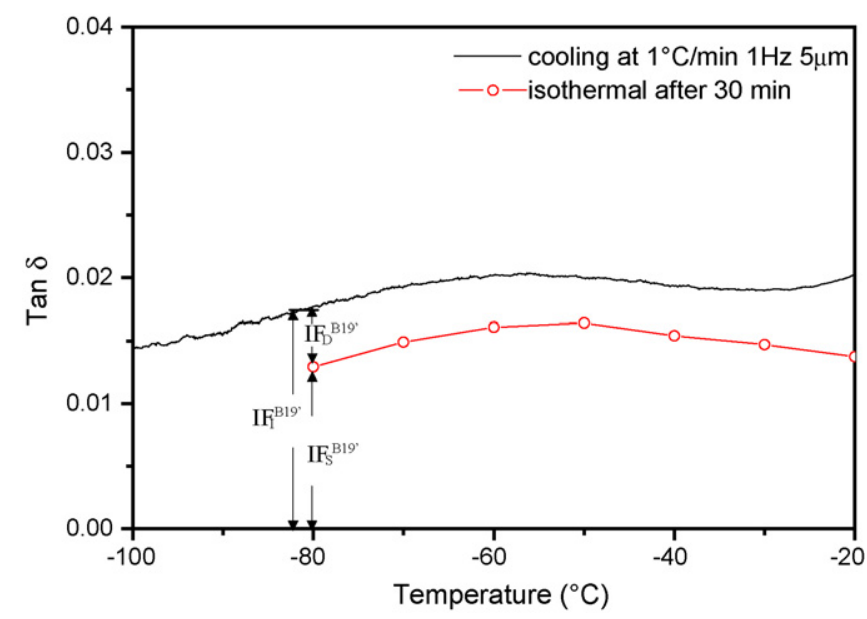

Fig. 6. Enlarged diagram of B19' martensite region in Fig. 3(a).

$0.1-10 \mathrm{~Hz}$ and $1-15 \mu \mathrm{m}$, respectively. This behavior is same as the damping characteristic of the inherent internal friction $\mathrm{IF}_{\mathrm{PT}}+\mathrm{IF}_{\mathrm{I}}$ of $\mathrm{B} 2 \rightarrow \mathrm{R}$ and $\mathrm{R} \rightarrow \mathrm{B} 19^{\prime}$ martensitic transformations which is also linearly proportional to $\sigma_{0} / v^{1 / 2}$ and independent of $\dot{T}[18]$. Therefore, the inherent internal friction $\mathrm{IF}_{\mathrm{PT}}+\mathrm{IF}_{\mathrm{I}}$ of $\mathrm{B} 2 \rightarrow \mathrm{R}$ and $\mathrm{R} \rightarrow \mathrm{B} 19^{\prime}$ martensitic transformations and $\mathrm{IF}_{\mathrm{S}}$ of the single R-phase and $\mathrm{B} 19^{\prime}$ martensite may originate from the similar damping mechanism. Since the inherent internal friction $\mathrm{IF}_{\mathrm{PT}}+\mathrm{IF}_{\mathrm{I}}$ is mainly generated from stress-assisted martensitic transformation and stress-assisted motions of twin boundaries [18], the damping mechanism of $\mathrm{IF}_{\mathrm{S}}^{\mathrm{R}}$ and $\mathrm{IF}_{\mathrm{S}}^{\mathrm{B} 19^{\prime}}$ is proposed to be contributed by the stress-assisted movements of twin boundaries in between the variants of R-phase and B19' martensite, respectively.

From Figs. 3-5, all the measured $\tan \delta$ values of $\mathrm{IF}_{\mathrm{S}}^{\mathrm{B} 2}$ are quite low and very close to those of $\mathrm{IF}_{\mathrm{I}}^{\mathrm{B} 2}$. This feature indicates that $\mathrm{IF}_{\mathrm{I}}^{\mathrm{B} 2}$ is mainly contributed by the $\mathrm{IF}_{\mathrm{S}}^{\mathrm{B} 2}$ while $\mathrm{IF}_{\mathrm{D}}^{\mathrm{B} 2}$ is insignificant in B2 parent phase. Also from Figs. 3-5, both $\tan \delta$ values of $\mathrm{IF}_{\mathrm{S}}^{\mathrm{R}}$ and $\mathrm{IF}_{\mathrm{S}}^{\mathrm{B} 19^{\prime}}$ are much higher than those of $\mathrm{IF}_{\mathrm{S}}^{\mathrm{B} 2} \cdot \mathrm{IF}_{\mathrm{S}}^{\mathrm{B} 2}$ exhibits a rather small intrinsic internal friction because its $\tan \delta$ only comes from the dynamic/static hysteresis of lattice defects [5]. On the other hand, from DMA results shown in Figs. $3-5$, both $\mathrm{IF}_{\mathrm{S}}^{\mathrm{R}}$ and $\mathrm{IF}_{\mathrm{S}}^{\mathrm{B} 19^{\prime}}$ have higher $\tan \delta$ values than those of $\mathrm{IF}_{\mathrm{S}}^{\mathrm{B} 2}$ due to their abundant twin boundaries in between the variants which can be easily moved by the external stress to accommodate the applied strain. This characteristic indicates that the effect of twin boundaries on internal friction is more dominant than that of the lattice defects/dislocations introduced by cold-rolled and annealed treatment. Since the internal friction of $\mathrm{IF}_{\mathrm{S}}^{\mathrm{R}}$ and $\mathrm{IF}_{\mathrm{S}}^{\mathrm{B} 19^{\prime}}$ are mainly contributed by stress-assisted motions of twin boundaries, the effect of defects/dislocations due to thermal/mechanical process on damping behavior can be neglected in this study. Furthermore, Figs. 3-5 also show that the $\tan \delta$ values of $\mathrm{IF}_{\mathrm{S}}^{\mathrm{R}}$ are always higher than those of $\mathrm{IF}_{\mathrm{S}}^{\mathrm{B} 19^{\prime}}$ measured at the same experimental parameter. This feature comes from the fact that the lower storage modulus $E_{0}$ in R-phase, as shown in Fig. 1, leads to the easier movement of twin boundaries in R-phase and hence dissipates more energy during damping than $\mathrm{B} 19^{\prime}$ martensite. 

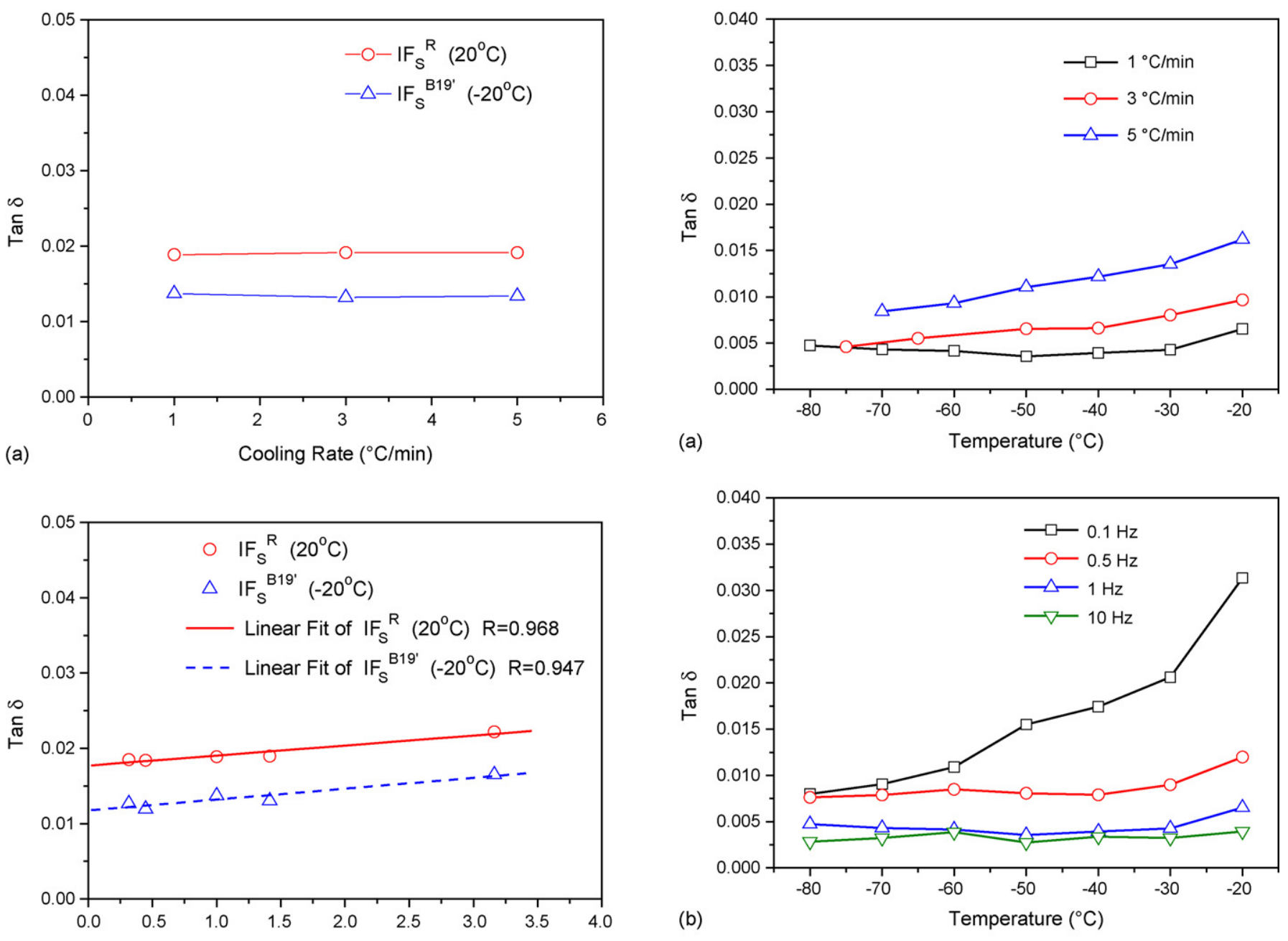

(b)

$1 / v^{1 / 2}\left(1 / \mathrm{Hz}^{1 / 2}\right)$
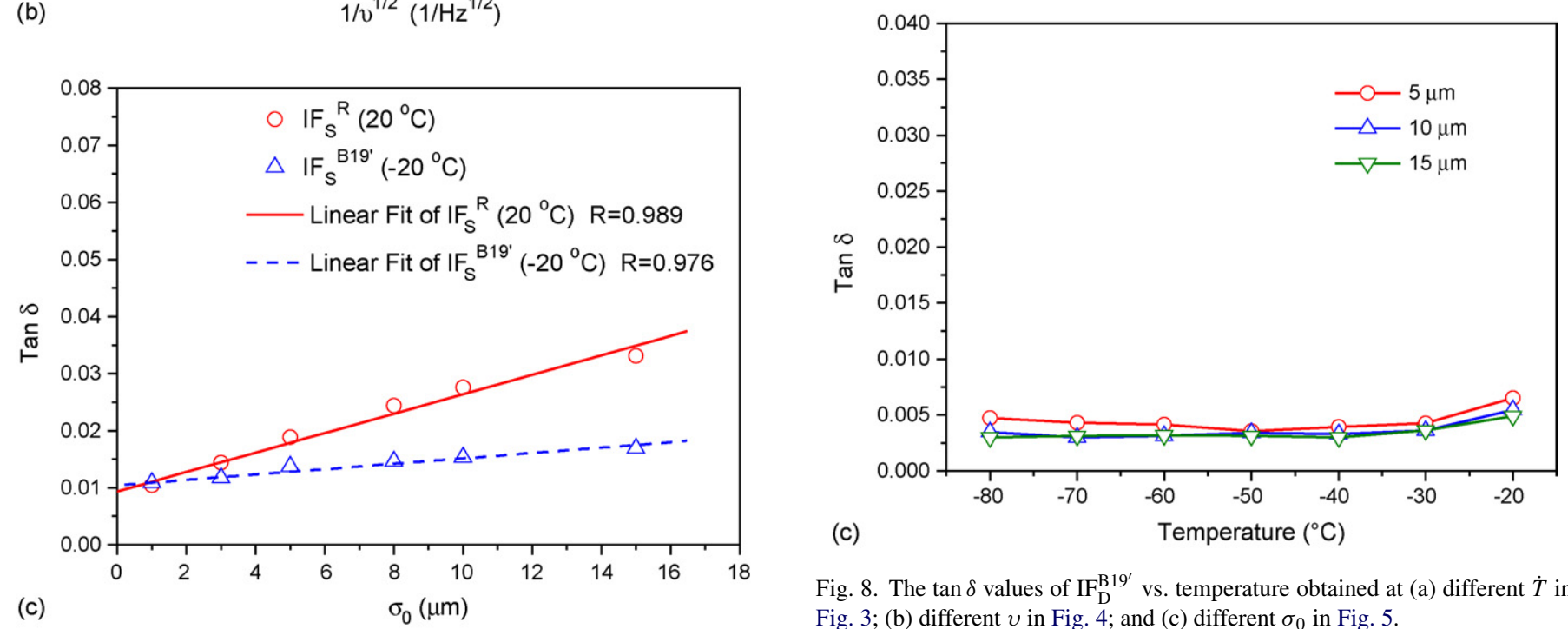

Fig. 8. The $\tan \delta$ values of $\mathrm{IF}_{\mathrm{D}}^{\mathrm{B} 19^{\prime}}$ vs. temperature obtained at (a) different $\dot{T}$ in Fig. 3; (b) different $v$ in Fig. 4; and (c) different $\sigma_{0}$ in Fig. 5.

Fig. 7. The tan $\delta$ values of $\mathrm{IF}_{\mathrm{S}}^{\mathrm{R}}$ and $\mathrm{IF}_{\mathrm{S}}^{\mathrm{B} 19^{\prime}}$ measured in Figs. $3-5$ at $20^{\circ} \mathrm{C}$ and $-20^{\circ} \mathrm{C}$ as a function of (a) $\dot{T}$; (b) $1 / v^{1 / 2}$; and (c) $\sigma_{0}$.

\section{2. $I F_{D}$ of $B 19^{\prime}$ martensite}

As illustrated in Fig. 6, when the specimen is kept isothermally at B $19^{\prime}$ martensite, the decayed $\tan \delta$ value represents the

$\mathrm{IF}_{\mathrm{D}}^{\mathrm{B} 19^{\prime}}$. The damping behavior of $\mathrm{IF}_{\mathrm{D}}^{\mathrm{R}}$ is suggested to be similar to that of $\mathrm{IF}_{\mathrm{D}}^{\mathrm{B} 19^{\prime}}$, but $\mathrm{IF}_{\mathrm{D}}^{\mathrm{R}}$ damping is difficult to measure due to the R-phase having a narrow existing temperature range, as shown in Fig. 1. As a result, only $\mathrm{IF}_{\mathrm{D}}^{\mathrm{B} 19^{\prime}}$ is discussed in detail in the following. 

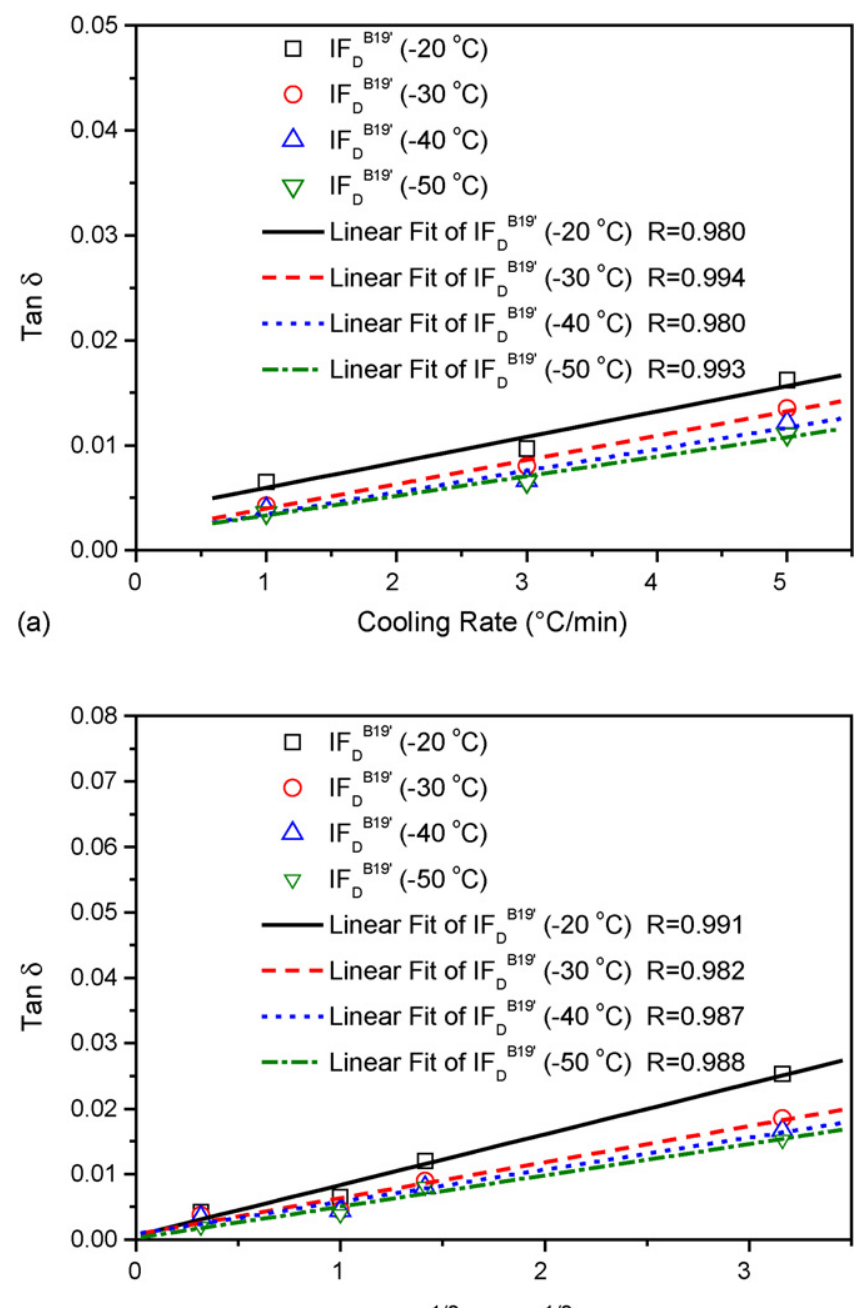

(b)

$$
1 / v^{1 / 2}\left(1 / \mathrm{Hz}^{1 / 2}\right)
$$

Fig. 9. The $\tan \delta$ values of $\mathrm{IF}_{\mathrm{D}}^{\mathrm{B} 19^{\prime}}$ measured in Fig. 8(a) and (b) at $-20^{\circ} \mathrm{C}$, $-30^{\circ} \mathrm{C},-40^{\circ} \mathrm{C}$ and $-50^{\circ} \mathrm{C}$ as a function of (a) $\dot{T}$ and (b) $1 / v^{1 / 2}$.

Fig. 8(a) plots the $\tan \delta$ values of $\mathrm{IF}_{\mathrm{D}}^{\mathrm{B} 19^{\prime}}$ versus. temperature in which $\mathrm{IF}_{\mathrm{D}}^{\mathrm{B} 19^{\prime}}$ is calculated by subtracting $\mathrm{IF}_{\mathrm{S}}^{\mathrm{B} 19^{\prime}}$ from $\mathrm{IF}_{\mathrm{I}} \mathrm{B} 19^{\prime}$ measured at different $\dot{T}$ in Figs. 3 and 6. The temperature deviation of $\mathrm{IF}_{\mathrm{S}}^{\mathrm{B} 19^{\prime}}$ and $\mathrm{IF}_{\mathrm{I}} \mathrm{B} 19^{\prime}$ has been corrected by the peak temperature shift of $\mathrm{R} \rightarrow \mathrm{B} 19^{\prime}$ transformation to eliminate the influence of $\dot{T}$. Fig. 8(b) and (c) show the tan $\delta$ values of $\mathrm{IF}_{\mathrm{D}}^{\mathrm{B} 19^{\prime}}$ as a function of temperature at different $v$ measured in Fig. 4 and at different $\sigma_{0}$ measured in Fig. 5, respectively. As shown in Fig. 8, the $\tan \delta$ values of $\mathrm{IF}_{\mathrm{D}}^{\mathrm{B} 19^{\prime}}$ increase with $\dot{T}$ but decreases with $v$ and almost independent of $\sigma_{0}$. Fig. 9(a) and (b) plot the $\tan \delta$ values of $\mathrm{IF}_{\mathrm{D}}^{\mathrm{B} 19^{\prime}}$ as a function of $\dot{T}$ and $1 / v^{1 / 2}$, respectively, in which $\mathrm{IF}_{\mathrm{D}}^{\mathrm{B} 19^{\prime}}$ is measured at different temperatures $\left(-20^{\circ} \mathrm{C},-30^{\circ} \mathrm{C},-40^{\circ} \mathrm{C}\right.$ and $-50^{\circ} \mathrm{C}$ ). As shown in Figs. 8(c) and 9, all the $\tan \delta$ values of $\mathrm{IF}_{\mathrm{D}}^{\mathrm{B} 19^{\prime}}$ measured at different temperatures increase linearly with increasing $\dot{T} / v^{1 / 2}$ but independent of $\sigma_{0}$ when the applied $\dot{T}$ and $v$ are in between $1-5^{\circ} \mathrm{C} / \mathrm{min}$ and $0.1-10 \mathrm{~Hz}$, respectively. This relationship is quite similar to that of $\mathrm{IF}_{\mathrm{S}}^{\mathrm{R}}$ and $\mathrm{IF}_{\mathrm{S}}^{\mathrm{B} 19^{\prime}}$ except that the term $\sigma_{0}$ is now replaced by $\dot{T}$. This feature demonstrates that the damping mechanism of $\mathrm{IF}_{\mathrm{S}}$ is generated by stress-assisted movements of twin boundaries while that of $\mathrm{IF}_{\mathrm{D}}$ is contributed by thermal-assisted motions of twin boundaries. Furthermore, Fig. 8 shows $\mathrm{IF}_{\mathrm{D}}^{\mathrm{B} 19^{\prime}}$ does not exhibit a broad peak at around $-60^{\circ} \mathrm{C}$ as $\mathrm{IF}_{\mathrm{S}}^{\mathrm{B} 19^{\prime}}$ shown in Figs. 3-5. This indicates the occurrence of relaxation peak only comes from the $\mathrm{IF}_{\mathrm{S}}^{\mathrm{B} 19^{\prime}}$, instead of the $\mathrm{IF}_{\mathrm{D}}^{\mathrm{B} 19^{\prime}}$.

\section{Conclusions}

The intrinsic internal friction $\mathrm{IF}_{\mathrm{I}}$ of R-phase and $\mathrm{B} 19^{\prime}$ martensite measured at constant $\dot{T}$ is both composed of a static term $\mathrm{IF}_{\mathrm{S}}$ which keeps steady after isothermal conditions and a dynamic term $\mathrm{IF}_{\mathrm{D}}$ which diminishes during isothermal conditions. Both $\tan \delta$ values of $\mathrm{IF}_{\mathrm{S}}^{\mathrm{R}}$ and $\mathrm{IF}_{\mathrm{S}}^{\mathrm{B} 19^{\prime}}$ are linearly proportional to $\sigma_{0} / v^{1 / 2}$ when the applied $v$ and $\sigma_{0}$ are in between $0.1-10 \mathrm{~Hz}$ and $1-15 \mu \mathrm{m}$, respectively. Consequently, the damping mechanism of $\mathrm{IF}_{\mathrm{S}}^{\mathrm{R}}$ and $\mathrm{IF}_{\mathrm{S}}^{\mathrm{B} 19^{\prime}}$ is associated with stressassisted movements of twin boundaries in between the variants of R-phase and B19' martensite, respectively. The $\tan \delta$ value of $\mathrm{IF}_{\mathrm{S}}^{\mathrm{R}}$ is higher than that of $\mathrm{IF}_{\mathrm{S}}^{\mathrm{B} 19^{\prime}}$ because the R-phase has softer storage modulus $E_{0}$ which leads to easier movement of twin boundaries in R-phase and dissipates more energy during damping. The $\tan \delta$ value of $\mathrm{IF}_{\mathrm{D}}^{\mathrm{B} 19^{\prime}}$ increases linearly with $\dot{T} / v^{1 / 2}$ and is independent of $\sigma_{0}$ when the applied $\dot{T}$ and $v$ are in between $1-5^{\circ} \mathrm{C} / \mathrm{min}$ and $0.1-10 \mathrm{~Hz}$, respectively. It implies that the damping mechanism of $\mathrm{IF}_{\mathrm{D}}^{\mathrm{R}}$ is due to thermal-assisted motions, instead of stress-assisted movements, of twin boundaries in B19' martensite. The occurrence of relaxation peak at about $-60^{\circ} \mathrm{C}$ only comes from the $\mathrm{IF}_{\mathrm{S}}^{\mathrm{B} 19^{\prime}}$, instead of the $\mathrm{IF}_{\mathrm{D}}^{\mathrm{B} 19^{\prime}}$.

\section{Acknowledgement}

The authors gratefully acknowledge the financial support for this research provided by the National Science Council (NSC), Taiwan, Republic of China, under Grants Nos. NSC94-2216E002-030.

\section{References}

[1] C.M. Wayman, T.W. During, in: T.W. During, K.N. Melton, D. Stöckel, C.M. Wayman (Eds.), Engineering Aspects of Shape Memory Alloys, Butterworth-Heinemam, London, 1990, pp. 3-20.

[2] K. Iwasaki, R. Hasiguti, Trans. JIM 28 (1987) 363.

[3] O. Mercier, K.N. Melton, Y. De Préville, Acta Metall. 27 (1979) 1467.

[4] S.K. Wu, H.C. Lin, T.S. Chou, Acta Metall. 38 (1990) 95.

[5] H.C. Lin, S.K. Wu, M.T. Yeh, Metall. Mater. Trans. A 24 (1993) 2189.

[6] K. Sugimoto, T. Mori, K. Otsuka, K. Shimizu, Scripta Metall. 8 (1974) 1341.

[7] Y. Liu, J. Van Humbeeck, R. Stalmans, L. Delaey, J. Alloys Compd. 247 (1997) 115.

[8] B. Coluzzi, A. Biscarini, R. Campanella, L. Trotta, G. Mazzolai, A. Tuissi, F.M. Mazzolai, Acta Mater. 47 (1999) 1965.

[9] S.K. Wu, H.C. Lin, J. Alloys Compd. 72-78 (2003) 355.

[10] S.H. Chang, S.K. Wu, Key Eng. Mater. 319 (2006) 9.

[11] J.F. Delorme, R. Schmid, M. Robin, P. Gobin, J. Phys. 32 (1971) C2C101. 
[12] W. Dejonghe, R. De Batist, L. Delaey, Scripta Metall. 10 (1976) 1125.

[13] J.E. Bidaux, R. Schaller, W. Benoit, J. Phys. 46 (1985) C10-C601.

[14] J. Van Humbeek, J. Stoiber, L. Delaey, R. Gotthardt, Z. Metallkd. 86 (1995) 1976.

[15] J.S. Zhu, R. Schaller, W. Benoit, Phys. Stat. Sol. A 108 (1988) 613.
[16] G. Gremaud, J.E. Bidaux, W. Benoit, Helv. Physica Acta 60 (1987) 947.

[17] J.E. Bidaux, R. Schaller, W. Benoit, Acta Metall. 37 (1989) 803.

[18] S.H. Chang, S.K. Wu, Scripta Mater. 55 (2006) 311.

[19] S.H. Chang, S.K. Wu, Scripta Mater. 50 (2004) 937. 